\title{
A Case of Acute Generalized Pustular Psoriasis of von Zumbusch Triggered by Hypocalcemia
}

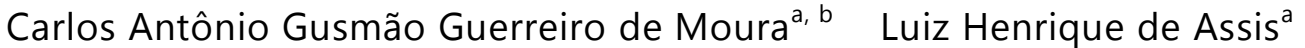 \\ Paulo Góes $^{a} \quad$ Fabiana Rosa $^{d}$ Victor Nunes $^{b} \quad$ Ítalo Magalhães Gusmão ${ }^{b}$ \\ Constança Margarida Sampaio $\mathrm{Cruz}^{\mathrm{a}, \mathrm{c}}$ \\ ${ }^{a}$ Programa de Residência de Clínica Médica do Hospital Santo Antônio, Obras Sociais Irmã \\ Dulce, ${ }^{b}$ Escola Bahiana de Medicina e Saúde Pública, and ${ }^{\mathrm{C} C u r s o}$ de Pós-graduação em \\ Medicina e Saúde Humana da Escola Bahiana de Medicina e Saúde Pública, Salvador, and \\ ${ }^{d}$ Faculdade de Medicina da UNIFENAS, Alfenas, Brazil
}

\section{Key Words}

Psoriasis · Hypocalcemia · Hypoparathyroidism · Psoriasis of von Zumbusch

\begin{abstract}
Psoriasis is an autoimmune disease triggered by different conditions in genetically susceptible people. It is characterized by variable cutaneous manifestations including localized or disseminated pustules. Generalized pustular psoriasis (GPP) has two main clinical forms: von Zumbusch psoriasis, characterized by severe erythrodermia and scaling skin after the resolution of pustules, and the annular form. GPP may also present severe extracutaneous manifestations including pneumonitis, heart failure and hepatitis. Old reports showed a relationship between hypoparathyroidism and hypocalcemia as triggers for GPP highlighting the importance of adequate workup of the patient and possible therapeutic changes in acute situations. Here, we present a case of severe von Zumbusch psoriasis with life-threatening complications triggered by severe hypocalcemia secondary to hypoparathyroidism successfully treated with aggressive calcium reposition.

(C) 2015 The Author(s)

Published by S. Karger AG, Basel
\end{abstract}

\section{Introduction}

Psoriasis is a chronic inflammatory disease that affects genetically susceptible people and is triggered by environmental factors and immune disorders. Such triggers might in- 
Case Reports in
Dermatology \begin{tabular}{l|l}
\hline Case Rep Dermatol 2015;7:345-351 \\
\hline DOI: 10.1159/000442380 & $\begin{array}{l}\text { ○ 2015 The Author(s). Published by S. Karger AG, Basel } \\
\text { www.karger.com/cde }\end{array}$ \\
\hline
\end{tabular}

Guerreiro de Moura et al.: A Case of Acute Generalized Pustular Psoriasis of von Zumbusch Triggered by Hypocalcemia

clude drugs, infections, and electrolyte disorders. It is characterized by recurrent skin disorder, histologically described as cutaneous inflammation, increased epidermal proliferation, hyperkeratosis, angiogenesis, abnormal keratinization, shortened maturation time, and parakeratosis. Psoriasis has many variants with cutaneous and extracutaneous manifestations. Generalized pustular psoriasis (GPP) is frequently associated with systemic symptoms.

Adult hypoparathyroidism is caused mainly by surgical complications, especially following thyroidectomy, with the risk of severe hypocalcemia. Its presentation may be asymptomatic or associated with several types of clinical features that appear abruptly or chronically $[1,2]$. One of the most specific manifestations of acute hypocalcemia is tetany related to neuromuscular irritability. However, many other manifestations have been attributed to hypocalcemia, including GPP $[3,4]$. Intracellular calcium plays an important role in regulating the proliferation and differentiation of keratinocytes. Some case reports have described psoriasis associated with disorders of calcium metabolism [5]. We here present a case of hypoparathyroidism as a trigger for severe acute GPP with life-threatening complications.

\section{Case Report}

A 73-year-old female patient, retired, was transferred to our institution for a diagnostic evaluation of diffuse erythrodermia 1 month before internment. The patient reported that the first lesions appeared as little periumbilical pruritic pustules. These lesions evolved to bullous lesions, with subsequent hyperkeratosis and desquamation, spreading to the extremities, the trunk and the face, associated with daily unmeasured fever, generalized edema, resting tremor, dyspnea and a decrease in her general state of health.

She denied mucosal involvement, similar previous episodes or recent exposure to new drugs/medicines. Her past medical history was related to systemic essential hypertension, well controlled with losartan, and total thyroidectomy 10 years ago, with irregular use of levothyroxine.

On admission, the patient was in a regular general state of health, with hypochromic mucous membranes, sinus tachycardia, and discrete tachypnea. Physical examination revealed diffuse crackles and wheezing, muscle weakness at the pelvic and shoulder girdle of grade 1 of 5, and resting tremor of the hands. There were no other movement disorders or ocular alterations. The skin showed erythrodermic lesions with disseminated desquamation (fig. 1), and discrete pustular lesions on the upper limbs without mucous lesions. Onycholysis was present associated with the destruction of the nail bed of the hands.

Liver enzymes, renal function and urinalysis were normal. Complete blood count showed anemia of chronic disease and mild leukocytosis. The remaining laboratory examinations showed hypoalbuminemia of $2.5 \mathrm{~g} / \mathrm{dl}$, creatine phosphokinase of $500 \mathrm{IU} / \mathrm{l}$, erythrocyte sedimentation rate of $80 \mathrm{~mm} / \mathrm{h}$, and severe hypocalcemia (total calcium $3.5 \mathrm{mEq} / \mathrm{dl}$ ).

Noteworthy was the hormonal panel: $\mathrm{TSH}=12.27 \mu \mathrm{IU} / \mathrm{ml}$, free $\mathrm{T} 4=1.1 \mathrm{ng} / \mathrm{dl}$, cholecalciferol $=34.6 \mathrm{ng} / \mathrm{ml}$, and parathyroid hormone $=13 \mathrm{pg} / \mathrm{ml}$. There was no monoclonal gammopathy found at protein electrophoresis. Anti-HIV-I, anti-HIV-II, anti-HTLV-I, anti-HTLV-II, VDRL, and antinuclear antibodies were negative.

The echocardiogram showed signs of dilated cardiomyopathy with diffuse hypokinesia and an ejection fraction of $28 \%$, without significant valve disease or segmental abnormalities. Chest X-ray was unremarkable except for congestive signs. A thigh skin biopsy was performed for diagnostic purpose, with histopathological findings consistent with pustular psoriasis (fig. 2). 
Guerreiro de Moura et al.: A Case of Acute Generalized Pustular Psoriasis of von Zumbusch Triggered by Hypocalcemia

The patient was treated with intravenous calcium and cholecalciferol, with regular use of oral levothyroxine. She progressed with significant improvement of her symptoms, with complete remission of the skin changes (fig. 3) and progressive improvement of her heart function.

Before discharge, another echocardiogram was performed showing complete recovery of the heart function, reinforcing the hypothesis of cardiomyopathy induced by GPP. All altered laboratory examinations returned to normal ranges. The clinical and the dermatology team decided to initiate methotrexate after the clinical improvement. The patient was referred to ambulatory follow-up.

\section{Discussion}

Psoriasis is a chronic inflammatory disease characterized by a dysregulation of immunity in genetically predisposed persons. The prevalence of the disease increases with the distance from the equator line [6-10].

Classically, psoriasis presents as chronic plaques with a variable extent of skin involvement. The diagnosis is eminently clinical; however, less common variants may require a histopathological study. Early alterations are seen on the papillary dermis, where there are perivascular infiltrations with vasodilation followed by epidermic alterations like acanthosis and parakeratosis [10].

Among other variants of psoriasis, the pustular form presents itself in many ways: GPP, impetigo herpetiformis, and two variants of localized pustular psoriasis (palmoplantar pustulosis and acrodermatitis continua of Hallopeau) [10,11].

Considering the patient's initial presentation of generalized pustulosis, two conditions must be investigated as possible mimickers of GPP: Sneddon's disease and acute generalized exanthematous pustulosis.

The main suspected diagnosis was GPP, since no monoclonal gammopathy was found, and she denied any use of medications usually associated with acute generalized exanthematous pustulosis (e.g. antimalarial). GPP was confirmed by histopathologic findings.

Interestingly, she presented with signs of heart failure and moderate hypoalbuminemia which are known as extracutaneous manifestations of severe GPP [9, 10, 12-14].

Myopathy was considered as part of hypothyroidism manifestations. The negative antinuclear antibodies with the absence of classic cutaneous findings of dermatomyositis and nearly normal creatine phosphokinase ruled out this hypothesis.

The most remarkable laboratory finding was severe hypocalcemia, justifying her resting tremor and possible association with severe psoriasis. All of this confirmed the diagnosis of severe GPP triggered by hypocalcemia related to untreated hypoparathyroidism after total thyroidectomy.

The GPP variant is usually preceded by other forms of psoriasis and has particular aspects on pathogenesis like mutations of the IL36RN gene. This gene codifies the receptor antagonist of interleukin-36 and has been associated with mucous lesions [15-17].

Many triggers for GPP have been described, especially gestation, infections, and drugs like glucocorticoids, amoxicillin and pegylated interferon. This case shows that the clinician must be aware of uncommon triggers like hypocalcemia. This electrolyte imbalance may present as a cause and consequence of disseminated disease, and the correct diagnosis is important to initiate early therapeutic intervention $[4,12,18,19]$.

GPP is one of the most serious variants of psoriasis, since it is usually not restricted to the skin and has variable systemic manifestations. Clinically, GPP has two forms: acute GPP 
Guerreiro de Moura et al.: A Case of Acute Generalized Pustular Psoriasis of von Zumbusch Triggered by Hypocalcemia

of von Zumbusch and generalized annular pustular psoriasis. The von Zumbusch GPP type is characterized by disseminated pustules on the trunk, extremities, and palmar-plantar regions that coalesce and then resolve, leaving erythema and extensive scaling.

Sometimes the diagnosis is difficult to make because the pustules are not present at the moment of examination, when only diffuse erythrodermia may be evident. GPP is one of the most serious variant of psoriasis because of life-threatening systemic complications including capillary leak syndrome, heart failure, acute respiratory distress syndrome, and sepsis [9-11].

Laboratory alterations compatible with systemic inflammation, such as leukocytosis, high erythrocyte sedimentation rate, hypoalbuminemia, and hepatic enzymes elevation, are common in GPP.

Hypocalcemia may be cause or consequence of the von Zumbusch psoriasis $[9,10,20]$. Many studies suggest that vitamin D plays a role in cell differentiation and proliferation of the skin. Furthermore, cell adhesion needs cadherins, which are molecules that depend on calcium $[5,21,22]$. These physiologic aspects may justify how some patients with hypoparathyroidism may precipitate psoriasis, including GPP, as presented here.

Different treatment options must be offered besides the classical therapy with oral retinoids, methotrexate, TNF- $\alpha$ blockers, and cyclosporine to treat GPP triggered by hypocalcemia. Calcium reposition associated with D vitamin is part of the essential treatment of acute GPP when hypocalcemia is identified $[3,18,22]$. Nevertheless, some patients, even with resolution of the triggers, need immunosuppressive therapy to reduce relapse rates.

We presented a case of acute GPP triggered by hypocalcemia related to primary hypoparathyroidism after total thyroidectomy. First, we emphasize the importance of the patient's history and a thorough physical examination, since the pustules may not be present at the physical examination. Second, one should be aware that psoriasis is not only a skin disease, but also a systemic inflammatory condition with variable manifestations. Finally, we point out that hypocalcemia is a trigger of GPP. Due to this situation, the physician should aggressively replenish calcium and vitamin D.

\section{Statement of Ethics}

The patient agreed to participate in the study with a written consent.

\section{Disclosure Statement}

The authors have no conflicts of interest to disclose.

\section{References}

1 Vanderlei FAB, Vieira JGH, Hojaij FC, Cervantes O, Kunii IS, Ohe MN, Santos RO, Abrahão M: Parathyroid hormone: an early predictor of symptomatic hypocalcemia after total thyroidectomy. Arq Bras Endocrinol Metabol 2012;56:168-172.

-2 Toniato A, Boschin IM, Piotto A, Pelizzo M, Sartori P: Thyroidectomy and parathyroid hormone: tracing hypocalcemia-prone patients. Am J Surg 2008;196:285-288.

-3 Lee Y, Nam Y-H, Lee J-H, Park J-K, Seo Y-J: Hypocalcaemia-induced pustular psoriasis-like skin eruption. Br J Dermatol 2005;152:591-593.

4 Kawamura A, Kinoshita MT, Suzuki H: Generalized pustular psoriasis with hypoparathyroidism. Eur J Dermatol 1999;9:574-576. 
Guerreiro de Moura et al.: A Case of Acute Generalized Pustular Psoriasis of von Zumbusch Triggered by Hypocalcemia

5 Premaor MO, Furlanetto TW: Vitamin D deficiency in adults: to better understand a new presentation of an old disease. Arq Bras Endocrinol Metabol 2006;50:25-37.

-6 Zelickson BD, Muller SA: Generalized pustular psoriasis. A review of 63 cases. Arch Dermatol 1991;127:1339-1345.

7 Parisi R, Symmons DPM, Griffiths CEM, Ashcroft DM: Global epidemiology of psoriasis: a systematic review of incidence and prevalence. J Invest Dermatol 2013;133:377-385.

-8 Augey F, Renaudier P, Nicolas J-F: Generalized pustular psoriasis (Zumbusch): a French epidemiological survey. Eur J Dermatol 2006;16:669-673.

-9 Borges-Costa J, Silva R, Gonçalves L, Filipe P, Soares de Almeida L, Marques Gomes M: Clinical and laboratory features in acute generalized pustular psoriasis: a retrospective study of 34 patients. Am J Clin Dermatol 2011;12:271-276.

10 Choon SE, Lai NM, Mohammad NA, Nanu NM, Tey KE, Chew SF: Clinical profile, morbidity, and outcome of adult-onset generalized pustular psoriasis: analysis of 102 cases seen in a tertiary hospital in Johor, Malaysia. Int J Dermatol 2014;53:676-684.

11 Gudjonsson JE; Elder JT: Psoriasis; in Goldsmith LA, Katz SI, Gilchrest BA, Paller AS, Leffell DJ, Wolff K (eds): Fitzpatrick's Dermatology in General Medicine, ed 8. New York, McGraw-Hill, 2012, vol 22, pp 197-231.

-12 Umezawa Y, Ozawa A, Kawasima T, Shimizu H, Terui T, Tagami H, Ikeda S, Ogawa H, Kawada A, Tezuka T, Igarashi A, Harada S: Therapeutic guidelines for the treatment of generalized pustular psoriasis (GPP) based on a proposed classification of disease severity. Arch Dermatol Res 2003;295(suppl 1):43-54.

13 Bachelez H: Pustular psoriasis. Ann Dermatol Venereol 2012;139(Suppl 2):S34-S38.

-14 Griffiths MR, Porter W, Fergusson-Wood LA, Adriaans B: Generalized pustular psoriasis complicated by acute respiratory distress syndrome. Br J Dermatol 2006;155:496-497.

15 Marrakchi S, Guigue P, Renshaw BR, Puel A, Pei X-Y, Fraitag S, et al: Interleukin-36-receptor antagonist deficiency and generalized pustular psoriasis. N Engl J Med 2011;365:620-628.

16 Li M, Han J, Lu Z, Li H, Zhu K, Cheng R, Jiao Q, Zhang C, Zhu C, Zhuang Y, Wang Y, Shi J, Guo Y, Wu R, Yao Z: Prevalent and rare mutations in IL-36RN gene in Chinese patients with generalized pustular psoriasis and psoriasis vulgaris. J Invest Dermatol 2013;133:2637-2639.

-17 Setta-Kaffetzi N, Navarini AA, Patel VM, Pullabhatla V, Pink AE, Choon SE, Allen MA, Burden AD, Griffiths CE, Seyger MM, Kirby B, Trembath RC, Simpson MA, Smith CH, Capon F, Barker JN: Rare pathogenic variants in IL36RN underlie a spectrum of psoriasis-associated pustular phenotypes. J Invest Dermatol 2013:133:1366-1369.

18 Boisseau-Garsaud AM, Legrain V, Hehunstre JP, Maleville J, Taïeb A: Treatment of psoriasis by oral calcitriol A study of 5 cases and review of the literature. Ann Dermatol Venereol 1993;120:669-674.

19 Perez A, Raab R, Chen TC, Turner A, Holick MF: Safety and efficacy of oral calcitriol (1,25-dihydroxyvitamin $D_{3}$ ) for the treatment of psoriasis. Br J Dermatol 1996;134:1070-1078.

20 Varman KM, Namias N, Schulman CI, Pizano LR: Acute generalized pustular psoriasis, von Zumbusch type, treated in the burn unit. A review of clinical features and new therapeutics. Burns 2014;40:e35-e39.

21 El-Wahed Gaber MA, El-Halim Kandil MA, El-Farargy SM, Galbet DAE: Beta-catenin expression in psoriasis. Indian Dermatol Online J 2015;6:13-16.

22 Kamangar F, Koo J, Heller M, Lee E, Bhutani T: Oral vitamin D, still a viable treatment option for psoriasis. J Dermatolog Treat 2013;24:261-267. 
Guerreiro de Moura et al.: A Case of Acute Generalized Pustular Psoriasis of von Zumbusch Triggered by Hypocalcemia

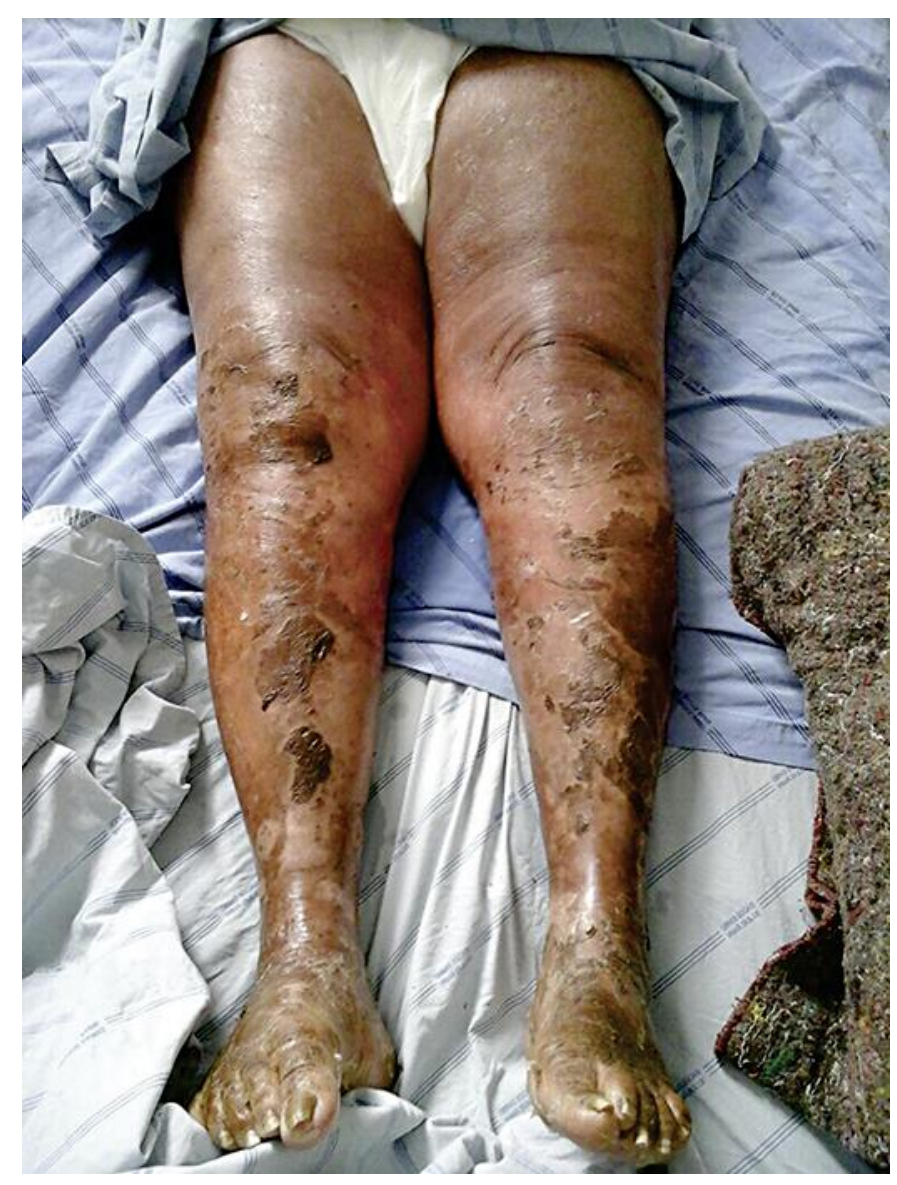

Fig. 1. Diffuse exfoliative lesions on the legs. 


\section{Case Reports in Dermatology}

\begin{tabular}{l|l}
\hline Case Rep Dermatol 2015;7:345-351 \\
\hline DOI: $10.1159 / 000442380$ & $\begin{array}{l}\text { (c) 2015 The Author(s). Published by S. Karger AG, Basel } \\
\text { www.karger.com/cde }\end{array}$ \\
\hline
\end{tabular}

Guerreiro de Moura et al.: A Case of Acute Generalized Pustular Psoriasis of von Zumbusch Triggered by Hypocalcemia

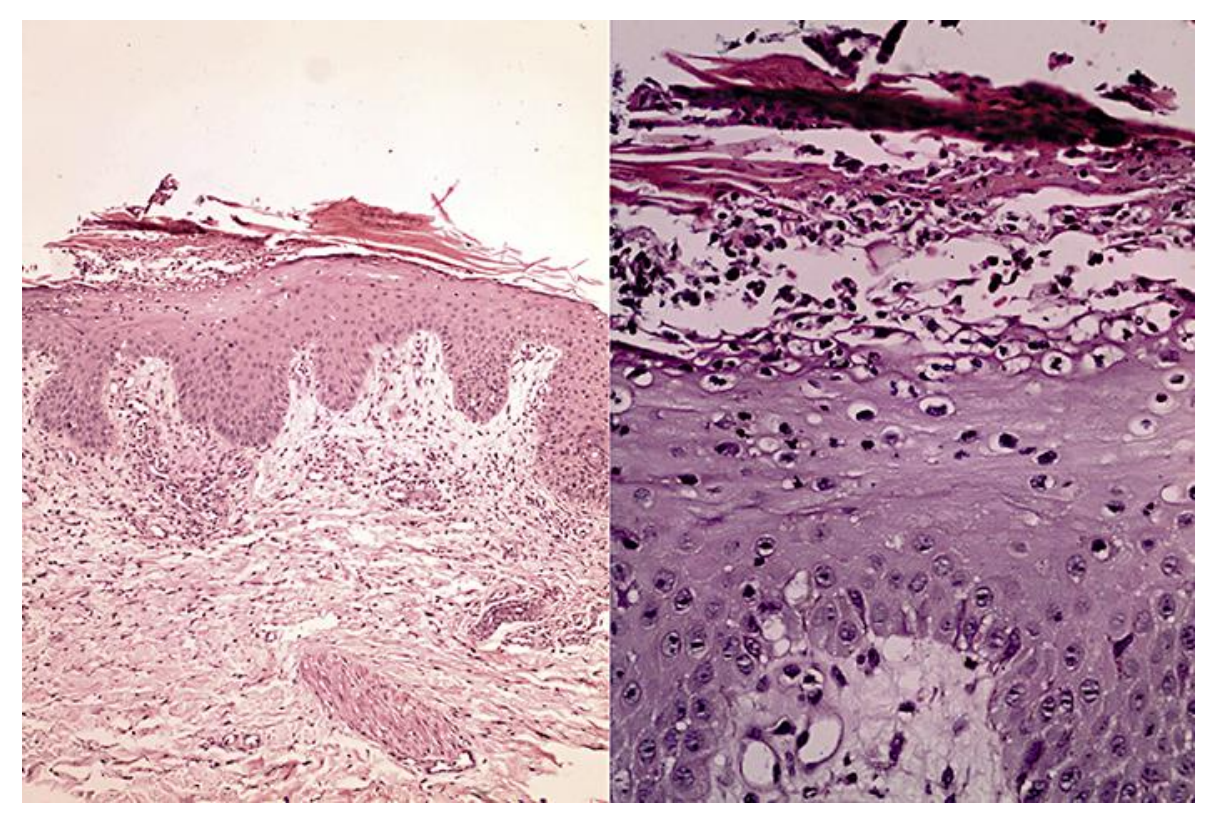

Fig. 2. a Epidermis with acanthosis, parakeratosis and moderate perivascular inflammatory infiltrate in the superficial dermis. b Higher magnification showing epidermis with exocytosis of neutrophils and small pustule formation in the stratum corneum.

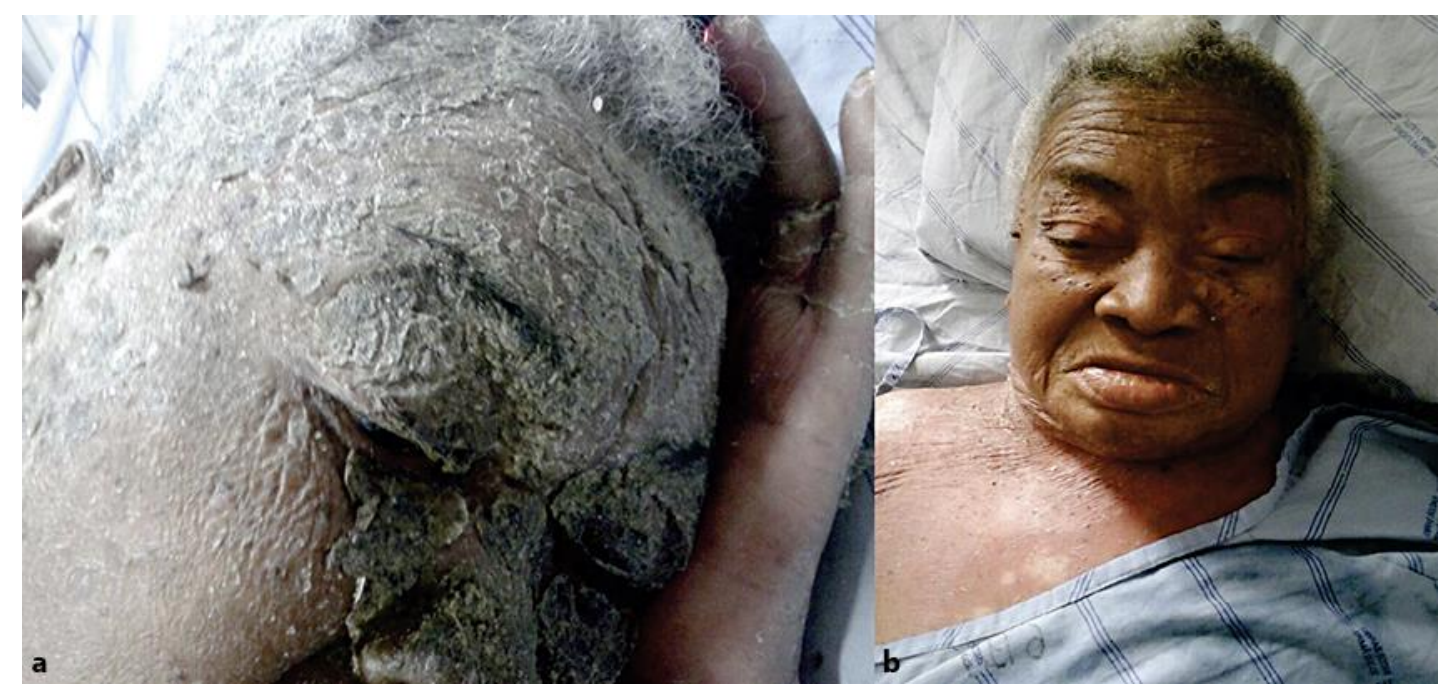

Fig. 3. a Intense facial hyperkeratosis as a clinical manifestation of acute GPP. b Improvement of facial hyperkeratosis after treatment of hypocalcemia. 